\title{
Radium behaviour during ferric oxi-hydroxides ageing
}

\author{
S. Bassot, D. Stammose and S. Benitah \\ Institute for Radiological Protection and Nuclear Safety (IRSN), \\ BP. 17, 92262 Fontenay-aux-Roses Cedex, France
}

\begin{abstract}
In uranium mill tailings, oxides and oxi-hydroxides are responsible of about $70 \%$ of the radium immobilization, half being associated to amorphous forms (mainly iron and manganese oxides/oxi-hydroxides). With time, crystallization of these amorphous forms can occur, inducing a redistribution of radium between solids and solution. If the amount of mobile radium increases, the impact of these tailings on the environment may become significant.

The aim of this study is to determine the amount of ${ }^{226} \mathrm{Ra}$ released in solution during the crystallization process of hydrous ferric oxi-hydroxide (HFO) containing ${ }^{226} \mathrm{Ra}$. A reproducible co-precipitation procedure is developed. The transformation of Ra-HFO co-precipitate in crystallized forms (goethite, hematite, ...) is studied by ageing amorphous solids at $40^{\circ} \mathrm{C}$ in different solutions.

After co-precipitation, about $20 \%$ of the initial ${ }^{226} \mathrm{Ra}$ present in solution is associated to amorphous HFO. At $40^{\circ} \mathrm{C}$, whatever the solution composition (MES or $\mathrm{NaClO}_{4}$ ), the solid evolution is very slow and, after 3-5 months, no significant amount of crystalline form is noticeable. Simultaneously, the amount of ${ }^{226} \mathrm{Ra}$ present in solution is constant in MES and $\mathrm{NaClO}_{4}$ medium. In comparison, ${ }^{226} \mathrm{Ra}$ sorption shows off inclusion of ${ }^{226} \mathrm{Ra}$ in Ra-HFO precipitate.
\end{abstract}

\section{INTRODUCTION}

Two types of minerals are present in uranium mill tailings: clastic minerals representing the nature of the original hostrock and the ore paragenesis (quartz, Na- and K-feldspars, muscovite, biotite, smectites, calcite, pyrite, ...) and autigenic minerals which have crystallized after the deposition of the tailings (gypsum, barite, jarosite, iron and manganese oxi-hydroxides, hexavalent uranium minerals, lead and uranium silicates) [1]. After the deposit of tailings, different mechanisms occur (pyrite dissolution during system oxidation, precipitation of oxi-hydroxides as cement around clastic and authigenic minerals) and tailings are submitted to diagenesis for a long period of time (until to reach equilibria). These tailings contain still a large amount of radionuclides issuing from the uranium chains $\left({ }^{238} \mathrm{U},{ }^{234} \mathrm{Th},{ }^{230} \mathrm{Th},{ }^{226} \mathrm{Ra},{ }^{210} \mathrm{~Pb}, \ldots\right)$, present on the different solid phases.

Sequential extractions conducted on Ecarpiere tailings in Vendée [2] (acid treatment) and on Lengenfed tailings in Germany [3] (alkaline treatment) show that iron (and manganese in a lower part) oxi-hydroxides are responsible of about $70 \%$ of ${ }^{226} \mathrm{Ra}$ sorption, half being fixed on amorphous forms. The rest part of the ${ }^{226} \mathrm{Ra}$ is fixed on gypsum, barite and silicates phases (clays, feldspars, micas, quartz). With time, amorphous solids can evolve towards crystalline forms and the radionuclides behaviour can be modified.

Previous studies [4] have shown that, at $40^{\circ} \mathrm{C}$, a crystallisation process of hydrous ferric oxi-hydroxides (HFO) occurs (formation of goethite) together with ${ }^{226} \mathrm{Ra}$ release in solution. But, the precipitation procedure used in theses studies led to some discrepancies in the data. 
The aim of this study is to develop a reproducible co-precipitation procedure in order to obtain a sufficient amount of Ra-HFO to allow an ageing study on a single and homogeneous HFO sample. Elsewhere, different solid characterization methods have been used in order to point out the solid modifications during the ageing process. In order to increase the crystallization rate, a temperature of $40^{\circ} \mathrm{C}$ has been chosen for the ageing experiment. This temperature seems the best compromise between an increase of the evolution rate and the "in-situ" temperature. At least, in order to study the possible modifications of the properties of solid sorption sites, ${ }^{226}$ Ra sorption onto amorphous and aged HFO is studied as a function of $\mathrm{pH}$.

\section{MATERIALS AND METHODS}

\subsection{Precipitation of ferrihydrite}

$80 \mathrm{~mL}$ of $0.1 \mathrm{M}$ ferric solution $\left(\mathrm{FeCl}_{3}, 6 \mathrm{H}_{2} \mathrm{O}\right.$ Normapur PROLABO in $0.1 \mathrm{M} \mathrm{HNO}_{3}$ ), and 0.33 to $0.45 \mathrm{~mL}$ of $\mathrm{RaCl}_{2}$ AMERSHAM solution (43.95 kBq. $\mathrm{mL}^{-1}$ of ${ }^{226} \mathrm{Ra}$ in $\mathrm{HCl} 0.5 \mathrm{M}$ ) is diluted in 220 to $280 \mathrm{~mL}$ of deionised water. The final ${ }^{226} \mathrm{Ra}$ concentration is between $5.9310^{-6}$ and $6.7510^{-6} \mathrm{mM}$ and the $\mathrm{Fe}(\mathrm{III})$ concentration was set at 22 to $26 \mathrm{mM}$, the $\mathrm{pH}$ being closed to 2 .

Coprecipitate of ${ }^{226} \mathrm{Ra}$ with $\mathrm{Fe}(\mathrm{III})$ was prepared by progressive addition of $1 \mathrm{M}$ low- $\mathrm{CO}_{2} \mathrm{NaOH}$ (NaOH Titrex) with a RADIOMETER automatic titration system (TIM900 titrator unit, ABU901 auto-burette with $20 \mathrm{~mL}$ burette) to acidified ${ }^{226} \mathrm{Ra}$ solution [5]. Base was slowly added to this solution (over 1 to $3 \mathrm{~h}$ ) to an endpoint of $\mathrm{pH}$. After about 15h, the $\mathrm{pH}$ of the slurry has slightly decreased and base was again added for adjustment to $\mathrm{pH}$. About 20 to 30mL of $\mathrm{NaOH}$ was required to reach $\mathrm{pH} 6$. The slurry was then centrifuged at $10000 \mathrm{G}$ during $15 \mathrm{~min}$ (KR-22i JOUAN apparatus, AK500-11 rotor). All the experiments were conducted in NALGENE bottles $(500 \mathrm{~mL})$. No sorption of ${ }^{226} \mathrm{Ra}$ on these vials was detected. In order to obtain sufficient amounts of solid, the solid fractions (ferrihydrite) of 3 precipitations were gathered and homogenised. For experiment A, the ferrihydrite was used without washing, while in experiment $\mathrm{B}$, the ferrihydrite was washed 3 times with $300 \mathrm{~mL}$ of deionised water before to be dried at ambient temperature.

\subsection{Crystallisation experiments of ferrihydrite}

Considering a previous study, $40^{\circ} \mathrm{C}$ was chosen for increasing reasonably the crystallisation rate. However, some ageing experiments have been conducted at $70^{\circ} \mathrm{C}$ in order to have a complete evolution of the solid.

The evolution experiment was realized through batch experiments using. About $2 \mathrm{~g}$ of ferrihydrite was added to $900 \mathrm{~mL}$ of solution (composition defined hereafter) in a $1000 \mathrm{~mL}$ polyethylene bottle, which is introduced in a 1-D bath shaker (SBD50 HETO) at fixed temperature of $40^{\circ} \mathrm{C}$. Two different solutions were used. Experiment A): the solution was a $0.1 \mathrm{M}$ solution of 2-(4-morpholino) ethane sulfonic acid (MES). MES was used to buffer the $\mathrm{pH}(\mathrm{pH}=6)$, and has a low trace element binding capacity and negligible impact on the rate of HFO transformation to crystalline product [6].

Experiment B): the solution was a $0.1 \mathrm{M}$ solution of $\mathrm{NaClO}_{4}$ which $\mathrm{pH}$ was adjusted to 6 . $\mathrm{ClO}_{4}{ }^{-}$ion didn’t complex Fe (III) and Ra (II).

Periodic samplings of the suspension (maintained through agitation) were conducted with a $20 \mathrm{~mL}$ pipette. In order to test the reproducibility of a such sampling procedure, 3 samples were realized each time, with solid/solution ratio between 0.2 and 5 g. $\mathrm{L}^{-1}$ and centrifuged at $10000 \mathrm{G}$ during 15min (KR-22i JOUAN apparatus, AK 50-22 rotor). For experiment B, the solids obtained after centrifugation were washed 3 times with $20 \mathrm{~mL}$ of deionised water, while for experiment A no washing occurs. For the 2 experiments, the solids were dried at ambient temperature before analysis. 


\section{$2.3{ }^{226}$ Ra sorption on ferrihydrite before and after evolution}

In order to study the ${ }^{226} \mathrm{Ra}$ sorption onto solids, ferrihydrite was precipitated like previously described $\left({ }^{226} \mathrm{Ra}\right.$ solution being replaced by the same volume of $\left.0.5 \mathrm{M} \mathrm{HCl}\right)$. After centrifugation and drying, a part of this precipitate was constituted the amorphous solid and stored. The other part of this precipitate was submitted to evolution in the same conditions than in 2.2), with a solid/solution ratio of about 2.5g. $\mathrm{L}^{-1}$ during 2 month. After centrifugation, the solid was dried at ambient temperature.

The ${ }^{226} \mathrm{Ra}$ sorption experiments were realized on these 2 solids following the same procedure. $0.1 \mathrm{~g}$ of solid was put in contact with $20 \mathrm{~mL}$ of solution containing the ${ }^{226} \mathrm{Ra}$ in NALGENE polyethylene tubes and shacked in a 3-D shaker (TURBULA). The ${ }^{226} \mathrm{Ra}$ solutions were prepared in $0.1 \mathrm{M} \mathrm{NaClO}_{4}$ (pH between 4 and 9) and in 0.1M MES (pH between 4 and 6). The temperature of the batch experiments was measured and varies from 24 to $30^{\circ} \mathrm{C}$. For each initial $\mathrm{pH}$, experiments were triplicate. After 24h of contact (previous studies have shown that this period was sufficient to reach equilibrium), the suspensions were centrifuged at $10000 \mathrm{G}$ during $15 \mathrm{~min}$ and the solutions obtained were filtrated (0.22 $\mu \mathrm{m}$ Millipore filter). Then, $\mathrm{pH}$ and ${ }^{226} \mathrm{Ra}$ measurements were realized. The amount of ${ }^{226} \mathrm{Ra}$ sorbed on HFO surface was deduced from the ${ }^{226} \mathrm{Ra}$ measure in solution, initially and after equilibrium.

\subsection{Solution analysis}

The pH was measured with a RADIOMETER automatic titration system (TIM900 titrator unit) by using a combined electrode (C2085, Red Rod electrode). ${ }^{226}$ Ra was measured by gamma spectrometry (186.2 keV) with a EURISYS hyperpur germanium detector (40\% of relative efficacity) on $15 \mathrm{~mL}$ of solution with a counting time of $1 \mathrm{~h}$. The detection limit of ${ }^{226} \mathrm{Ra}$ is $4.7 \mathrm{~Bq} \cdot \mathrm{mL}^{-1}$. The $\mathrm{Fe}^{3+}$ concentration was measured with a VARIAN atomic absorption spectrometer (Spectra 220 FS) with a detection

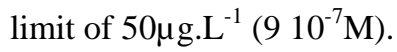

\subsection{Solid analysis}

X-ray diffraction were realised with a PHILIPS PW1729 X-ray diffractometer system. The specific surface area of the solids was measured with a COULTER SA3100 apparatus (using $\mathrm{N}_{2}$ adsorption with a BET model). Preliminary studies have defined the degassing conditions of solids analysed $\left(30^{\circ} \mathrm{C}\right.$ during $\left.15 \mathrm{~h}\right)$. The microscopic observations have been realized with a S-3500N HITACHI secondary electron microscope (SEM).

\section{EXPRESSION OF THE ${ }^{226}$ RA RESULTS}

$$
\begin{aligned}
& \text { Percentage of radium sorbed }(\%)=\left(\frac{A_{\text {initial }}-A_{\text {final }}}{A_{\text {initial }}}\right) \cdot 100 \\
& \text { Distribution coefficient of }{ }^{226} \mathrm{Ra} \mathrm{K}_{\mathrm{d}}\left({ }^{\mathrm{L} \cdot \mathrm{kg}^{-1}}\right)=\left(\frac{\mathrm{A}_{\text {initial }}-\mathrm{A}_{\text {final }}}{\mathrm{A}_{\text {initial }}}\right) \cdot \frac{\mathrm{V}_{\text {solution }}}{\mathrm{M}_{\text {solid }}}
\end{aligned}
$$

with $\quad \mathrm{A}_{\text {initial }} \quad$ : activity in blank solution (sorption) and in initial solution (crystallisation) (Bq)

$\mathrm{A}_{\text {final }} \quad:{ }^{226} \mathrm{Ra}$ activity in solution after contact with solid (Bq)

$\mathrm{M}_{\text {solid }} \quad$ : mass of solid (g)

$\mathrm{V}_{\text {solution }}$ : volume of solution (L) 


\section{RESULTS AND DISCUSSION}

\subsection{Characterization of ferrihydrite (before and during evolution)}

In order to follow the evolution with time of the solid, different characterization techniques have been used.

SEM observations allow to point out the beginning of crystallisation process (Figure 1). Freshly precipitated HFO (a) is constituted with smooth particles whereas, after 8 days at $70^{\circ} \mathrm{C}$, nodules are observed on the surface.

This evolution of HFO is confirmed by X-ray diffraction patterns. Different steps of evolution are presented on Figure 2. For the freshly precipitated HFO, no peak appears and the baseline for small angles is very high, traducing the absence of crystalline forms in the analysed solid. With time, characteristics peaks of goethite and hematite minerals appear and baseline level diminishes. At $70^{\circ} \mathrm{C}$ and after 36 days, the most part of HFO is crystallized.

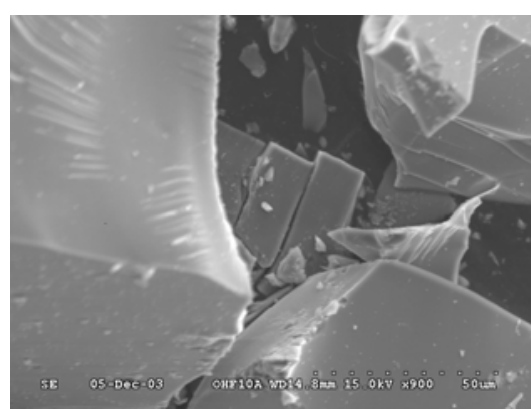

a)

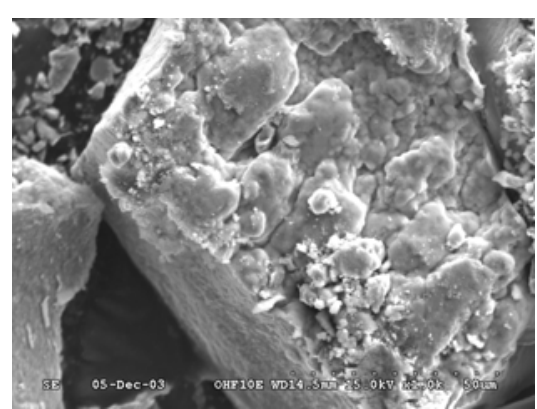

b)

Figure 1. Photography of a) ferrihydrite before evolution $(G=x 900)$ and of $b)$ ferrihydrite after 8 days of contact with $0.1 \mathrm{M} \mathrm{NaClO}_{4}$ at $70^{\circ} \mathrm{C}(\mathrm{G}=\mathrm{x} 1000)$.

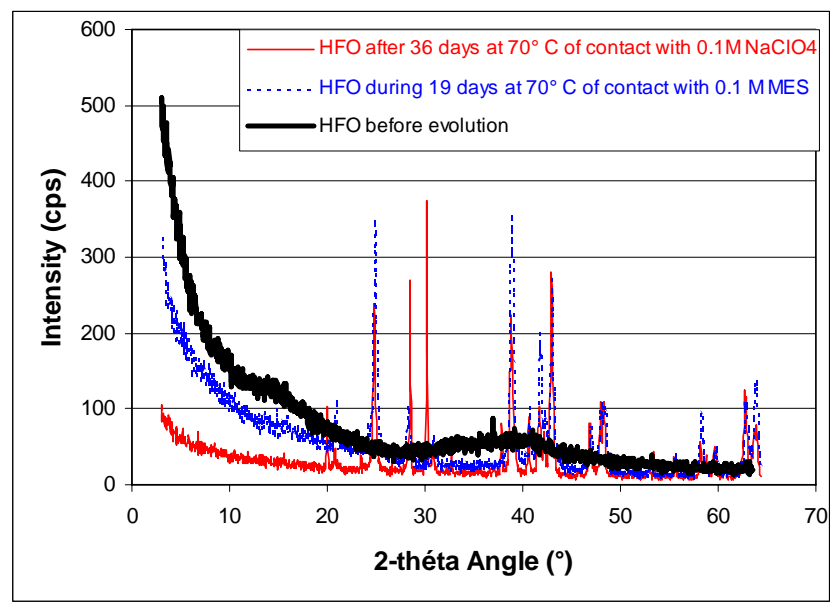

Figure 2. X-ray diffraction patterns of HFO at different evolution steps ( $\mathrm{t}=$ 0-no evolution, 19 days, 36 days).

$\mathrm{N}_{2}$ sorption/de-sorption curves allow the determination of specific surface area of solids according to BET model. Generally, specific surface area of amorphous solids is higher than those of crystallized ones. The specific surface areas of solids corresponding to different step of ageing are presented in Table 1. 
Table 1. Specific surface area values (BET) measured on HFO in different conditions.

\begin{tabular}{|c|c|}
\hline Evolution conditions & Specific surface area (BET) $\left(\mathrm{m}^{2} \cdot \mathrm{g}^{-1}\right)$ \\
\hline No evolution & $250.8 \pm 12.5$ \\
\hline Evolved in $0.1 \mathrm{M} \mathrm{MES}$ at $70^{\circ} \mathrm{C}$ during 19 days & $39.5 \pm 2.0$ \\
\hline Evolved in $0.1 \mathrm{M} \mathrm{NaClO}$ & at $70^{\circ} \mathrm{C}$ during 36 days \\
\hline
\end{tabular}

These data show that, with time, specific surface area decrease from $251 \mathrm{~m}^{2} \cdot \mathrm{g}^{-1}$ for freshly precipitated $\mathrm{HFO}$ to about $16 \mathrm{~m}^{2} \cdot \mathrm{g}^{-1}$ for an aged solid $\left(70^{\circ} \mathrm{C}\right.$ during 36 days in $\left.0.1 \mathrm{M} \mathrm{NaClO} 4\right)$. This decrease confirms a beginning of solid modification.

\subsection{Radium behaviour during HFO ageing}

After HFO precipitation, about $20 \%$ of ${ }^{226} \mathrm{Ra}$ is fixed to the solid, the iron concentration being lower than $100 \mu \mathrm{g} . \mathrm{L}^{-1}\left(1.810^{-6} \mathrm{M}\right)$. Moreover, the washing step of co-precipitate removes 60 to $80 \%$ of the ${ }^{226} \mathrm{Ra}$ present on the solid. This amount corresponds to the solution still contained in the amorphous precipitate (strongly hydrated). Lefebvre [4] has reported a precipitation yield closed to 90\% and no ${ }^{226} \mathrm{Ra}$ release during the washing step. It seems that our procedure, which allow the obtainment of a single sample for ageing experiment, has a limited precipitation rate for ${ }^{226} \mathrm{Ra}$.

Anyway, the solid have been gently shacked at $40^{\circ} \mathrm{C}$ in $\mathrm{MES}$ and $\mathrm{NaClO}_{4}$. The distribution coefficient of ${ }^{226} \mathrm{Ra}$ and the ${ }^{226} \mathrm{Ra}$ concentration in solution are plotted (Figure 3) as a function of time for 2 different solutions (MES, $\mathrm{NaClO}_{4}$ ). In MES medium, ${ }^{226} \mathrm{Ra}$ concentration in solution remains constant and no peak is observed on XRD patterns of the solids sampled at different times. No crystallisation of HFO occurs in MES after 3 months of ageing at $40^{\circ} \mathrm{C}$. During this period, MES solution ensures the buffering of the $\mathrm{pH}$ (between 5.7 and 6.2 for 3 months). In $\mathrm{NaClO}_{4}$ medium, ${ }^{226} \mathrm{Ra}$ concentration present in solution doesn't vary with time. Simultaneously, the $\mathrm{pH}$ decreases from 6 to 3.7 after 5 months. Like for MES experiment, no peaks are observed on the DRX patterns of the different solids. It seems that, whatever the solution composition, after 3 months, no crystallization of the solids has occurred. For these two experiments, the ${ }^{226} \mathrm{Ra}$ distribution coefficient $\left(\mathrm{K}_{\mathrm{d}}\right)$ varies between 250 and 410L.kg ${ }^{-1}$ in MES and between 100 and 220L.kg-1 in $\mathrm{NaClO}_{4}$ medium.

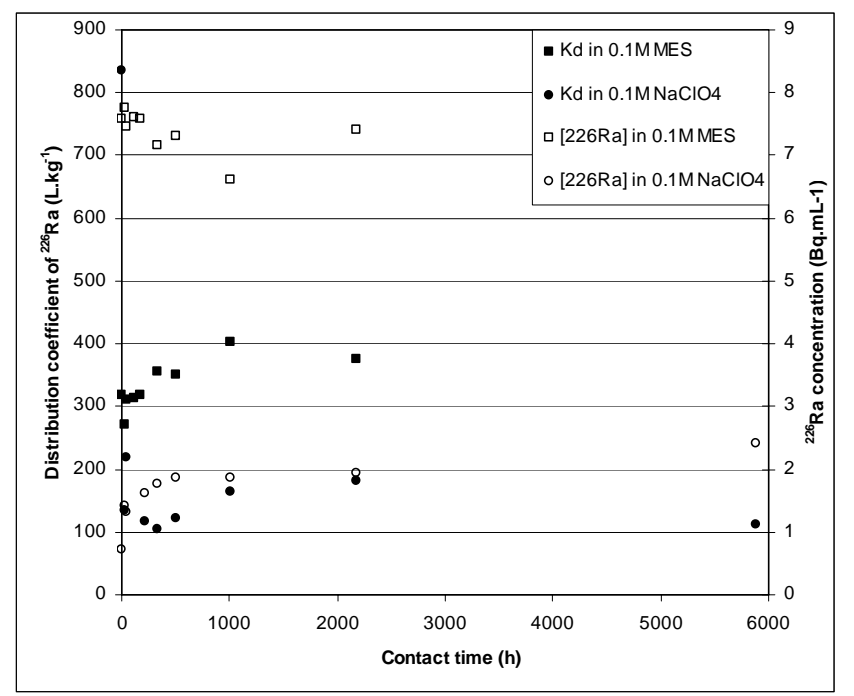

Figure 3. Evolution of distribution coefficient of ${ }^{226} \mathrm{Ra}$ and ${ }^{226} \mathrm{Ra}$ concentration in solution in function of time in $0.1 \mathrm{M}$ MES and in $0.1 \mathrm{M} \mathrm{NaClO}_{4}$. 
$\mathrm{N}_{2}$ sorption/de-sorption curves obtained for solids aged in MES medium are presented on Figure 4. These curves, obtained for freshly precipitated $\mathrm{HFO}$ and aged $\mathrm{HFO}\left(40^{\circ} \mathrm{C}\right.$ in $0.1 \mathrm{M} \mathrm{MES}$ during 20 weeks), present different shapes. No hysterisis is present for freshly precipitated HFO, while, for aged HFO, a hysterisis is present, traducing the presence of mesopores on the solid (pores size between 2 and 50nm). Amorphous HFO has begun to evolve (modification of the pores distribution) but no crystals were formed or formed in a too small quantity to be detected by XRD patterns.

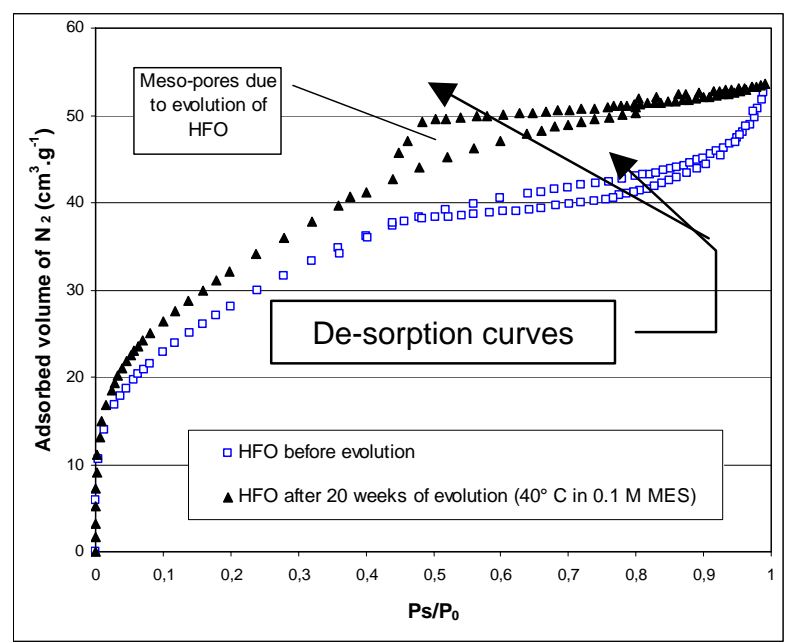

Figure 4. $\mathrm{N}_{2}$ adsorption/desorption curves on HFO samples.

\subsection{Radium sorption onto HFO}

The ${ }^{226}$ Ra sorption onto 2 solids, freshly precipitated HFO and 2 months aged, has been studied as a function of $\mathrm{pH}$. The sorption curves are plotted on Figure 5. In both cases, the sorption increases with $\mathrm{pH}$, low sorption for low $\mathrm{pH}$ and strong sorption for high $\mathrm{pH}$. But, in the case of aged HFO, the sharp increase of sorption seems to appear for lower $\mathrm{pH}$ than for fresh HFO. The characteristics of the sorption sites (acidity constants, sorption constants) of HFO have been modified by the evolution of solid.

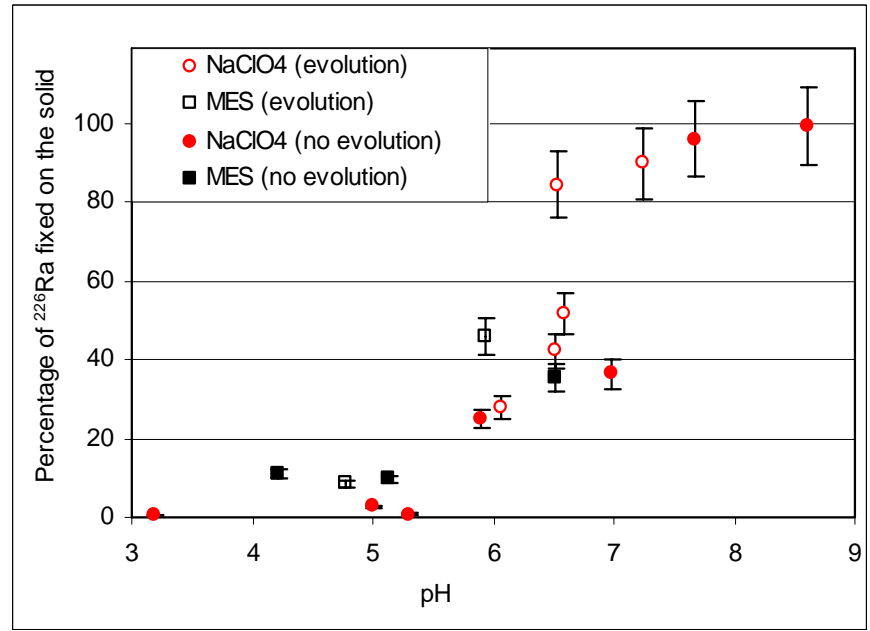

Figure 5. Evolution of percentage of ${ }^{226} \mathrm{Ra}$ fixed on $\mathrm{HFO}$ in function of $\mathrm{pH}$. 
In MES and $\mathrm{NaClO}_{4}$, distribution coefficient of ${ }^{226} \mathrm{Ra}$ values determined for freshly precipitated HFO in these sorption experiments (respectively about 200 and $140 \mathrm{~L}_{\mathrm{kg}} \mathrm{kg}^{-1}$ at $\mathrm{pH}$ 6) are lower than those determined in the evolution experiment. It can be due to the incorporation of all or part of ${ }^{226} \mathrm{Ra}$ in Ra-HFO precipitate.

\section{CONCLUSION}

This study has pointed out the importance of the precipitation procedure onto the nature of precipitate, the precipitation rate and on its evolution. No significant evolution of the solids $\left(40^{\circ} \mathrm{C}\right.$ for $3-5$ months) was detectable by DRX measurements. But some modifications of organisation of the solid (porosity) can be pointed out through specific surface area measurements. Moreover, the ${ }^{226} \mathrm{Ra}$ sorption studies show that sorption properties of solid sites are modified during this ageing.

\section{References}

[1] F. Ruhlmann, in Proceedings of the International Conference on Waste Management, Tucson, 1996, edited by Laser Options (Tucson).

[2] S. Somot, M. Pagel, J. Thiry, C.R. Acad. Sci. Paris, Earth \& Planetary Sciences 325 (1997) 111-118.

[3] S. Bassot, Mobilité du radium et de l'uranium dans un site de stockage de résidus issus du traitement de minerais d'uranium, Thesis, Besançon, France (1997).

[4] C. Lefebvre, Influence de la cristallisation des oxyhydroxydes de fer sur la rétention du radium, du zinc, de l'arsénic et de l'uranium, Thesis, Paris XI, France (2002).

[5] R. G. Ford, K.M. Kemner, P. M. Bertsch, Geochim. Cosmochim. Acta 63 (1999) 39-48.

[6] M. H. Bradbury, B. Baeyens, Geochim. Cosmochim. Acta 63 (1999) 325. 